\title{
Uso de reator de leito estático granular no tratamento de águas residuárias de laticínios
}

\author{
Tamara Daiane de SOUZA ${ }^{1}$, Alisson Carraro BORGES ${ }^{2 *}$, Diego LOPES ${ }^{2}$, \\ Paola Alfonsa Vieira LO MONACO ${ }^{3}$, Antonio Teixeira de MATOS $^{4}$
}

\author{
${ }^{1}$ Faculdade de Engenharia Civil, Universidade Federal do Sul e Sudeste do Pará, Marabá, PA, Brasil. \\ ${ }^{2}$ Departamento de Engenharia Agrícola, Centro de Ciências Agrárias, Universidade Federal de Viçosa, Viçosa, MG, Brasil. \\ ${ }^{3}$ Instituto Federal do Espírito Santo, Santa Teresa, ES, Brasil. \\ ${ }^{4}$ Departamento de Engenharia Sanitária e Ambiental, Escola de Engenharia, Universidade Federal de Minas Gerais, \\ Belo Horizonte, MG, Brasil. \\ *E-mail: borges@ufv.com
}

Recebido em abri1/2018; Aceito em março/2019.

RESUMO: Objetivou-se, com a realização deste trabalho, avaliar o desempenho de um reator de leito estático granular no tratamento de solução sintética simulando águas residuárias de indústrias de laticínios. Amostras do afluente e do efluente do reator foram submetidas às análises de $\mathrm{DQO}$, turbidez, condutividade elétrica e pH. De acordo com os resultados obtidos, pode-se concluir que o sistema mostrou ser alternativa promissora para tratamento de águas residuárias oriundas de laticínios, apresentando, com um tempo de detenção hidráulica de 48 horas, eficiências médias de $96 \%$ na remoção de DQO e $93 \%$ na de turbidez. Ademais, observou-se que proporcionou a manutenção da alcalinidade no meio, possibilitando que o processo fosse conduzido em condições de estabilidade. $\mathrm{O}$ tratamento da água residuária sintética estudada com o uso do reator de leito estático granular proporcionou atendimento à legislação para lançamento de efluentes em corpos hídricos no que tange à concentração de matéria orgânica.

Palavras-chave: tratamento anaeróbio; efluente de laticínios; remoção de DQO; reator biológico.

\section{Use of the static granular bed reactor in treatment of dairy wastewater}

\begin{abstract}
The aim of this work was to evaluate the performance of a static granular bed reactor to treat synthetic solution simulating wastewater from dairy industries. Influent and effluent samples were analyzed for COD, turbidity, electrical conductivity and $\mathrm{pH}$. According to the results obtained, it can be concluded that the system proved to be a promising alternative for treatment of effluents from dairy industry, presenting, with a hydraulic residence time of 48 hours, average efficiencies of $96 \%$ for COD removal and $93 \%$ for turbidity removal. Furthermore, it was observed the maintaining of alkalinity in the medium, indicating an operation under stable conditions. The treatment of dairy wastewater using static granular bed reactor provided appropriate effluent according to law for discharging on water bodies regarding organic matter concentration.
\end{abstract}

Keywords: anaerobic treatment; wastewater of dairy products; COD removal; biological reactor.

\section{INTRODUÇÃO}

O saneamento ambiental é importante ferramenta para promoção do desenvolvimento socioeconômico de uma sociedade, assim, esforços devem ser empreendidos para se obter a conservação da qualidade sanitária e ambiental dos mananciais existentes.

A indústria de laticínios é considerada uma das maiores fontes de efluentes industriais, o que tem como consequência uma expressiva contribuição na poluição dos corpos hídricos. A água é utilizada em todas as etapas do processamento do leite, incluindo limpeza e sanitização dos equipamentos, resfriamento e aquecimento do leite e lavagem de pisos $(\mathrm{OH}$ et al., 2014).

As águas residuárias geradas nas indústrias de processamento de produtos lácteos geralmente contêm alta demanda bioquímica de oxigênio (DBO) e demanda química de oxigênio (DQO) resultantes de proteínas, gorduras e carboidratos, incluindo lactose, e altos níveis de nitrogênio e fósforo (FARIZOGLU; UZUNER, 2011; OH et al., 2014).
A adoção de sistemas simplificados de tratamento dessas águas residuárias torna-se recomendável, sobretudo se tais sistemas forem sustentáveis, eficientes, apresentando, principalmente, custos reduzidos e simplicidade operacional. Dentre os processos simplificados mais promissores, registrase o modelo desenvolvido na Universidade Estadual de Iowa (Estados Unidos), denominado de sludge granular bed reactor (SGBR), ou seja, reator de leito estático granular (ELLIS; $\mathrm{MACH}, 2004)$.

O reator SGBR utiliza um regime de escoamento hidráulico descendente, por meio de uma camada densa e fixa de ativos grânulos anaeróbios, que podem acomodar grandes concentrações de sólidos suspensos. De acordo com Debik; Coskun (2009), o SGBR funciona como filtro biológico anaeróbio, uma vez que não envolve sistemas de mistura (configuração de recirculação) e tem meios granulares estáveis.

A alta densidade de grânulos otimiza o contato entre os microrganismos na superfície do meio de suporte com a água residuária, resultando em menor volume construído, menores 
custos e maior produção de energia renovável na forma de biogás. A água residuária afluente é distribuída uniformemente em todo o biorreator e percola através da camada de grânulos (ELLIS; MACH, 2004). Dessa forma, esse sistema é menos suscetível à "lavagem" de sólidos (carreamento de sólidos juntamente com gases e água de saída do reator), que ocorre em reatores anaeróbios do tipo manta de lodo de escoamento ascendente (ELLIS; MACH, 2004; DEBIK; COSKUN, 2009).

Embora ainda não amplamente utilizado, o SGBR é opção promissora de tratamento anaeróbio, em razão da elevada eficiência de remoção de DQO, tal como constatado em estudos realizados por Debik; Coskun (2009) e Lim; Fox (2011) que utilizaram esse sistema no tratamento de águas residuárias, respectivamente, de abatedouro de aves e de suinocultura.

Apesar das vantagens citadas, ainda são escassas as pesquisas quanto à tratabilidade de águas residuárias de laticínios nesse tipo de configuração. Dessa maneira, o presente estudo foi proposto, a fim de se obter maior conhecimento sobre o comportamento do reator SGBR quando utilizado no tratamento de águas residuárias de laticínios. Objetivou-se, portanto, com a realização deste trabalho, avaliar a partida e eficiência do reator SGBR no tratamento desses efluentes.

\section{MATERIAL E MÉTODOS}

A configuração do sistema de tratamento foi composta por três compartimentos situados em cotas diferentes para que a água residuária se movimentasse por gravidade sob escoamento descendente, tal como esquema representado no esquema disposto na Figura 1. O compartimento de nível superior era composto por um recipiente plástico, de capacidade de 5 litros, onde se armazenava o afluente. A parte superior do recipiente continha um orifício, que era mantido aberto para que não houvesse fermentação do afluente a ser tratado.

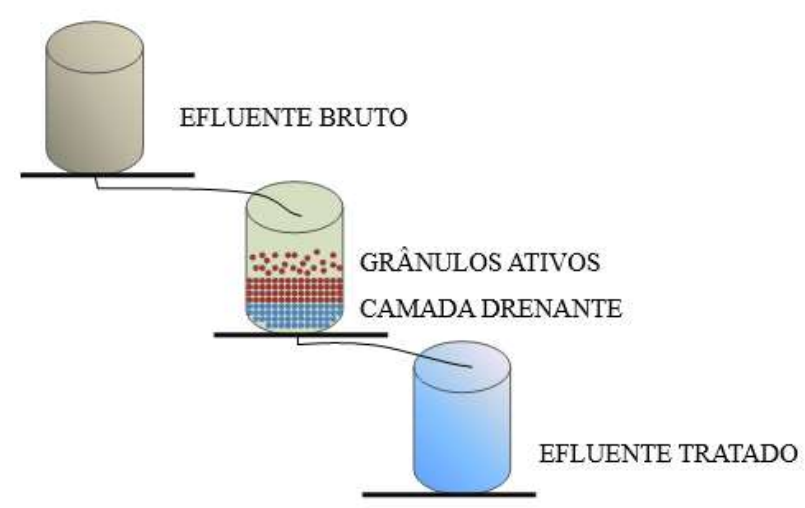

Figura 1. Desenho esquemático do sistema de tratamento. Figure 1. Schematic drawing of the treatment system.

O compartimento intermediário, o qual funcionava como reator SGBR propriamente dito, era composto por outro recipiente de 5 litros onde era degradada parte da matéria orgânica presente na água residuária. Ao fundo deste recipiente havia uma camada drenante composta por brita "número zero" (4,8 a 9,5 mm) e, acima desta, areia. Sobre esta camada, foram colocados os grânulos ativos, responsáveis pela degradação do material orgânico. Para a obtenção dos grânulos, utilizou-se lodo de excesso oriundo de um reator tipo UASB, coletado na estação de tratamento de esgoto. O lodo foi alimentado com resíduos de suinocultura, ou seja, adicionaram-se resíduos brutos de suinocultura (inóculo) ao lodo durante 3 meses, a fim de se obter grânulos mais bem formados e constituídos por microrganismos biologicamente ativos.

No compartimento inferior, representado por um recipiente de 20 litros, era coletado o efluente do reator SGBR. Os compartimentos eram unidos por conexões com controle de vazão. Estes dispositivos permitiam a regulação da vazão por abertura e fechamento dos orifícios. Todos os compartimentos foram cobertos por plástico de cor preta, para que não houvesse penetração de luz e o desenvolvimento de organismos fototróficos.

O afluente a ser tratado foi constituído por uma solução sintética, simulando água residuária de laticínios (ARL), tal como utilizado por outros autores, em trabalhos correlatos, como o de Campos et al. (2004). Para a formulação e padronização, foi escolhido o leite integral Viçosa tipo C, diluído em água. Posteriormente, foram feitas análises de demanda química de oxigênio e, a partir destas, foi obtido um fator de diluição. Adquiriu-se, então, um padrão de água residuária feito sempre nas mesmas proporções e, para os parâmetros aqui avaliados, tal mistura representava satisfatoriamente a ARL. Tal formulação representa o efluente gerado a partir do enxágue para remoção de resíduos de leite o que ficam aderidos em latões de leite, tanques diversos (transporte, armazenamento, produção), tubulações de leite bombas, equipamentos e utensílios diversos utilizados diretamente na produção.

Para determinar a vazão utilizada ao longo do período de tempo da experimentação, primeiramente estipulou-se um tempo de detenção hidráulica de 48 horas para degradação do material orgânico contido na água residuária. Considerando-se o volume útil do reator, foi obtida uma vazão de $0,0120 \mathrm{~mL} \mathrm{~s}$ ${ }^{1}$ (ou $0,0432 \mathrm{~L} \mathrm{~h}^{-1}$ ), a qual era regulada na entrada e na saída do reator por meio de "equipos". Para certificação de se ter vazão constante durante todo o período, a mesma era aferida pelo método volumétrico, e caso fosse necessário, era regularizada duas vezes ao dia, às 7 e $18 \mathrm{~h}$.

O tempo de operação do reator foi de 56 dias e, nesse período, foram monitoradas a DQO (duas vezes por semana), o $\mathrm{pH}$, alcalinidade à bicarbonato e ácidos graxos voláteis (semanalmente), além da turbidez e condutividade elétrica (ao final do experimento). As análises foram realizadas seguindose o preconizado no Standard Methods for the Examination of Water and Wastewater (APHA, 2017), exceto as aferições de alcalinidade, que foram feitas de acordo com o método Kapp (1984) descrito por Buchauer (1998).

\section{RESULTADOS}

A caracterização da ARL sintética foi realizada em laboratório, sendo que a mesma apresentou DQO de $3640 \pm 122$ $\mathrm{mg} \mathrm{L} \mathrm{L}^{-1}, \mathrm{pH}$ de $7,1 \pm 0,24$, alcalinidade medida como bicarbonato de $35,33 \pm 10,3 \mathrm{mg} \mathrm{L}^{-1}$, turbidez de $1999 \pm 50$ UNT e condutividade elétrica de $131,9 \pm 22,5 \mu \mathrm{S} \mathrm{cm}^{-1}$. Esses valores são semelhantes aos aferidos por Janczukowicz et al. (2008) e Saléh et al. (2009) analisando ARL reais.

$\mathrm{Na}$ Tabela 1 estão apresentados os valores médios de turbidez e condutividade elétrica do efluente tratado e do afluente e, na Figura 2, visualizam-se os padrões de eficiência de remoção e de concentrações efluentes de DQO ao longo do tempo depois da partida/operação do SGBR. 
Tabela 1. Valores de turbidez e condutividade elétrica do afluente e efluente tratado.

Table 1. Turbidity and electrical conductivity values of the affluent and treated effluent.

\begin{tabular}{lcc}
\hline Amostra & $\begin{array}{l}\text { Turbidez } \\
(\mathrm{UNT})\end{array}$ & $\begin{array}{l}\text { Condutividade elétrica } \\
\left(\mu \mathrm{S} \mathrm{cm}^{-1}\right)\end{array}$ \\
\hline Afluente & $1.040,0$ & 154,0 \\
Efluente Tratado & 74,0 & 454,0 \\
\hline
\end{tabular}

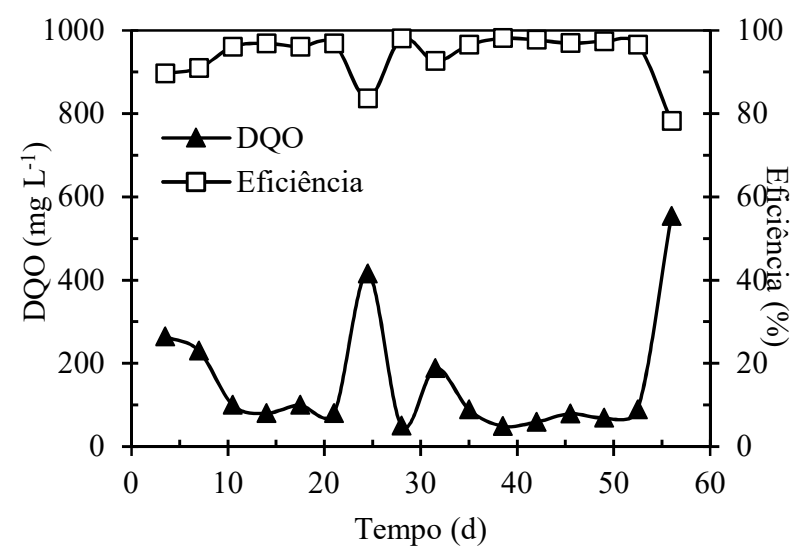

Figura 2. Valores de DQO e a eficiência de remoção da mesma durante o período de operação do reator SGBR.

Figure 2. COD values and COD removal efficiency during the period of operation of the SGBR reactor.

Nos resultados apresentados de redução de turbidez (Tabela 1), constatou-se redução média de 93\% desse parâmetro. Sendo a turbidez uma medida indireta dos sólidos suspensos, pode-se inferir que o tratamento se mostrou apropriado para a remoção desses materiais.

Pode-se observar na Figura 2 que o reator apresentou alta eficiência na remoção de DQO, sendo a média durante o período de operação do sistema, de $96 \%$.

$\mathrm{Na}$ Figura 3 apresentam-se os valores de $\mathrm{pH}$ e dos teores alcalinidade e ácidos graxos voláteis no efluente durante a operação do reator SGBR. De acordo com o que está apresentado nessa figura, verifica-se que o $\mathrm{pH}$ em torno da neutralidade no afluente também contribuiu para que se obtivesse condições ideais para degradação do material orgânico no interior do reator, já que, de acordo com Schoenhals et al. (2007), é apropriado e recomendado em tratamentos anaeróbios que o pH esteja entre 6,5 e 7,5.

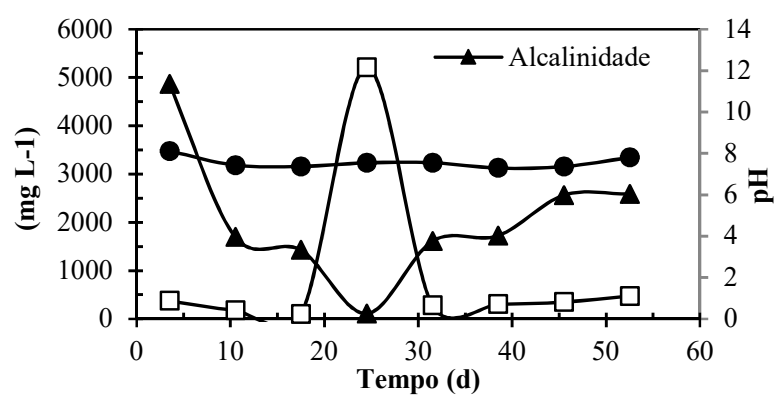

Figura 3. Teores de alcalinidade e ácidos graxos voláteis durante o período de operação do reator SGBR.

Figure 3. Alkalinity and volatile fatty acids contents during the period of operation of the SGBR reactor.

Quadros et al. (2010) reforçam que mudanças no $\mathrm{pH}$ do meio afetam sensivelmente as bactérias envolvidas no processo de digestão. De acordo com esses autores, a faixa de pH na operação dos biodigestores é de 6,0 a 8,0 , tendo como ponto ideal o $\mathrm{pH} 7,0$, que ocorre naturalmente quando o reator está funcionando de maneira apropriada.

$\mathrm{Na}$ quarta semana do experimento, verificou-se redução da alcalinidade no sistema e, consequentemente, aumento nos níveis de ácidos graxos voláteis. No mesmo período, notou-se redução na eficiência do tratamento o que, possivelmente, se deva ao decréscimo ocorrido na temperatura do ar, como pode ser verificado na Figura 4. A elevada influência da temperatura externa é justificada em razão de se tratar de um reator de bancada, em que qualquer alteração no ambiente externo altera a dinâmica do tratamento anaeróbio, devido à sua reduzida dimensão.

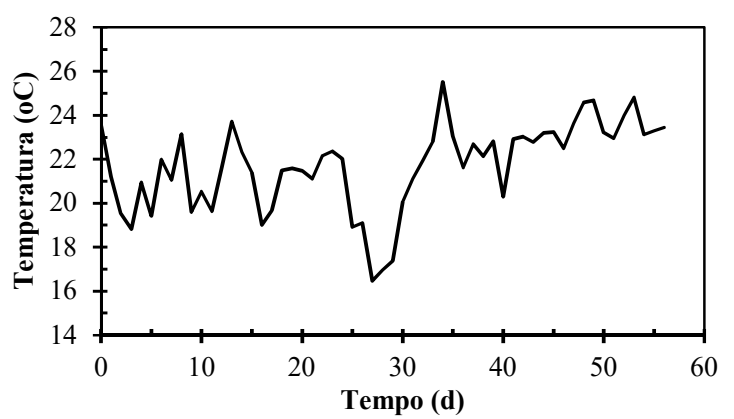

Figura 4. Temperatura do ar ao longo do período de experimentação. Figure 4. Air temperature throughout the experiment period.

Na Figura 5 visualiza-se uma fotografia de uma amostra da água afluente e efluente do sistema, na qual se pode verificar expressiva redução de cor aparente da amostra proporcionada pelo SGBR.

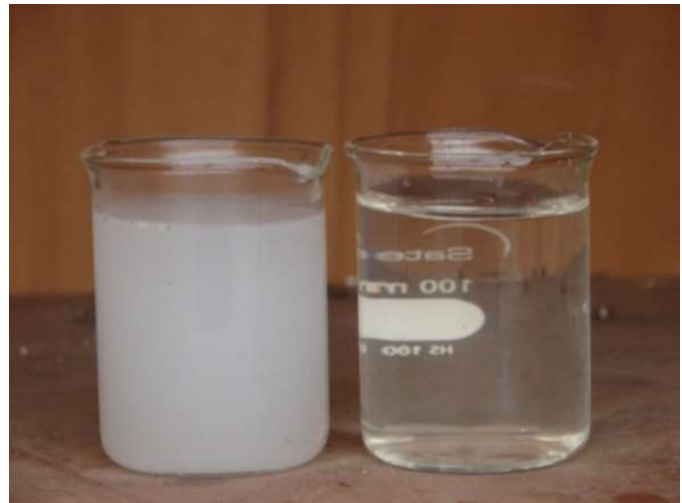

Figura 5. Aspectos visuais de amostra do afluente e efluente do SGBR.

Figure 5. Visual aspects of inlet and outlet samples of the SGBR.

\section{DISCUSSÃO}

Tratamentos biológicos possuem alguns requisitos para desempenho satisfatório do sistema, como por exemplo, a biodegradabilidade da água residuária. Neste caso, como se tratou uma ARL sintética composta por uma solução de leite integral, tal requisito certamente foi atendido.

Outro fator crucial é a presença de nutrientes, essencial ao crescimento da biomassa microbiana, tais como nitrogênio e fósforo. Neste quesito, a ARL sintética não possui a relação citada como ideal para o tratamento anaeróbio, que é de 350:5:1 (DQO:N:P) (CHERNICHARO, 1997). Todavia, o fato de se utilizar, como inoculo, água residuária de suinocultura, sabidamente rica em nutrientes, este fator passou a não ser limitante para o bom desempenho do reator durante o período de monitoramento. A condutividade elétrica é uma propriedade que é diretamente proporcional à concentração de 
íons presentes na solução. De acordo com os resultados apresentados na Tabela 1, verifica-se aumento de, aproximadamente, três vezes na concentração de íons no efluente tratado, quando comparado aos presentes no afluente. Tal fato é verificado com frequência em efluentes de reatores anaeróbios, uma vez que, após algum tempo de funcionamento do sistema, inicia-se a mineralização de grânulos e do material orgânico do afluente, que vão se decompondo com liberação de íons, principalmente, $\mathrm{NH}_{4}{ }^{+}$e $\mathrm{PO}_{4}{ }^{3-}$, aumentando suas concentrações no efluente ou mantendo-se próximo às presentes no afluente, tal como pôde ser observado no trabalho de Santos et al. (2006), no tratamento de esgoto sanitário utilizando um reator UASB.

Somado a isto, o fato de se ter usado a água residuária de suinocultura, sabidamente rica em nutrientes, como indutivo à granulação, pode ter contribuído para a saturação iônica da superfície dos grânulos. Assim, como os íons possuem alta solubilidade, com o decorrer do funcionamento do sistema, foram solubilizados para a água em tratamento.

Com relação a remoção de DQO, resultados semelhantes foram encontrados por Park et al. (2012) que, ao utilizarem o SGBR no tratamento de água residuária de laticínios, obtiveram eficiências de remoção de DQO entre 80 e $90 \%$ para tempo de detenção hidráulica (TDH) de 9 a 96 h sob taxas de carregamento orgânico de 0,63 a 9,72 $\mathrm{kg} \mathrm{m}^{-3} \mathrm{~d}^{-1}$ de DQO. Lim; Fox (2011) também relataram eficiências variando entre 77 a 94\% de eficiência de remoção de DQO em tratamento de água residuária de suinocultura quando foi utilizado o SGBR. Evans; Ellis (2010), ao avaliarem o desempenho de reator de mesmo modelo no tratamento de água residuária sintética de indústria de alimentos, obtiveram remoção de DQO em torno de $91 \%$.

As elevadas eficiências obtidas na remoção dos parâmetros avaliados neste trabalho podem ser atribuídas a diversos fatores que, combinados, favoreceram a atividade biológica dos microrganismos presentes nos grânulos do SGBR. Dentre estes fatores, podem ser destacados a temperatura, o tempo de detenção hidráulica (TDH), o pH, além do material que foi inoculado para estimular o crescimento de grânulos ativos no reator, conforme discutido a seguir. Ademais, a própria configuração do reator, por utilizar alta densidade de grânulos, é citada como motivo das altas eficiências obtidas (ELLIS; MACH; 2004; DEBIK; COSKUN, 2009; PARK et al., 2012).

Durante o período de operação do SGBR, a temperatura média diária do ar foi $21,6{ }^{\circ} \mathrm{C}$ e, considerando-se que o experimento foi conduzido no interior de uma casa de vegetação, esperam-se temperaturas médias acima desse valor no interior da construção. De acordo com SZYMANSKI et al. (2010), quando o lodo inoculado no reator é proveniente de estações de tratamento de esgotos (ETE), o qual é adaptado a temperaturas mesofílicas, recomenda-se a operação do reator na faixa de temperatura de 30 a $40{ }^{\circ} \mathrm{C}$, aproximadamente.

$\mathrm{O}$ TDH de $48 \mathrm{~h}$ pôde também ter sido importante fator de influência nas altas eficiências de remoção obtidas, já que tempos maiores proporcionam, teoricamente, contato maior entre a água residuária e os grânulos presentes no interior do reator, culminando na digestão do material orgânico na água residuária em tratamento.

Em reatores anaeróbios, a alcalinidade apresenta-se como parâmetro de extrema importância. A relação entre a alcalinidade e a acidez baseia-se na capacidade de tamponamento do sistema, ou seja, no potencial do sistema em neutralizar os ácidos formados no processo. De acordo com o que está apresentado na Figura 3, pode-se observar que houve manutenção da alcalinidade no sistema, indicando condições favoráveis ao processo de degradação da matéria orgânica.

Por fim, o fato de o lodo ter sido inoculado com água residuária de suinocultura, para estimular o crescimento de grânulos ativos, pode ter contribuído para o fornecimento de nutrientes essenciais às bactérias, tais como nitrogênio e enxofre, sabidamente contidos nesse tipo de água residuária.

As oscilações nas eficiências do tratamento, de 85 a $99 \%$ são, potencialmente, um reflexo das variações das temperaturas externas, pois, como citado anteriormente, um reator em escala piloto, devido as suas reduzidas dimensões, é afetado diretamente pela temperatura ambiente. Todavia, é importante ressaltar que não houve temperaturas extremas o suficiente $\left(<10^{\circ} \mathrm{C}\right)$ para tornar o tratamento inviável, durante o período de operação do reator.

O Conselho Nacional do Meio Ambiente (CONAMA) não estabelece limites em termos de DQO para o lançamento de efluentes. No que se refere à DBO, por meio da Resolução 430 de 2011, o Conselho estabeleceu que, no tratamento de águas residuárias agroindustriais, o sistema apresente eficiência mínima de $60 \%$ de remoção de DBO (BRASIL, 2011). Apesar desse parâmetro não ter sido avaliado, tal valor foi certamente alcançado, uma vez que o tratamento biológico promove, em sua maioria, a decomposição das frações biodegradáveis. Portanto, pode-se inferir que o tratamento de efluentes de laticínios com o uso do SGBR proporcionou atendimento à legislação para lançamento de efluentes em corpos hídricos.

O reator anaeróbio UASB é amplamente utilizado para tratamento de águas residuárias. Em experimento realizado por Campos et al. (2004), utilizando esse sistema, em escala piloto, no tratamento de água residuária de laticínios, avaliou-se a eficiência do reator para diferentes tempos de detenção hidráulica (TDH), tendo sido alcançada a eficiência máxima de 52\% na remoção de DQO, para um TDH de 18 h. A eficiência obtida pelos autores foi inferior à encontrada neste trabalho, no entanto, deve-se considerar que o TDH utilizado neste trabalho $(48 \mathrm{~h})$ foi consideravelmente maior que $\mathrm{o}$ utilizado pelos citados autores. Schoenhals et al. (2007) avaliaram dois sistemas UASB em escala real, no tratamento de água residuária de suinocultura, e verificaram máximas de remoção de DQO de 40\%, justificando a baixa eficiência ao inadequado manejo do reator no que se refere ao controle da velocidade ascensional, fato inexistente quando se emprega $o$ reator SGBR. Evans; Ellis (2010), ao compararem o desempenho de um reator UASB com um reator SGBR, ambos operando com TDH de $8 \mathrm{~h}$, no tratamento de água residuária sintética de indústria de alimentos, verificaram que o reator SGBR proporcionou remoção de $91 \%$ na DQO, enquanto que o reator UASB alcançou remoção de 78\%.

Outro aspecto importante a ser salientado é que, não raramente, verifica-se o arraste de partículas sólidas presentes na manta de lodo em reatores UASB. Tal fato deve-se ao regime hidráulico ascendente, em que a água efluente bem como os gases de saída podem carrear grânulos para fora do sistema. Consequentemente, perdas de material biologicamente ativo bem como diminuição de eficiência com relação à remoção de sólidos suspensos têm sido observadas em reatores UASB. Tal como verificado por Rodrigues et al. (2010) que, em análise do desempenho de reator UASB no tratamento de águas residuárias de suinocultura, constataram ser o aumento na concentração de sólidos no efluente do reator devido ao arraste de partículas ou excesso de lodo no reator. 
Isso indicou, segundo os autores, irregularidades operacionais do reator. Já no sistema SGBR, devido à inserção de uma camada drenante e sendo o escoamento descendente, a perda dos grânulos é minimizada, implicando em alta eficiência na remoção de sólidos suspensos, que neste trabalho foi analisada com base na turbidez. Assim, devido a sua simplicidade operacional, baixo custo e elevada eficiência, o SGBR pode ser considerado como um reator com bom potencial para uso em escala plena em indústrias de laticínios.

\section{CONCLUSÕES}

O sistema SGBR mostrou ser alternativa promissora para tratamento de águas residuárias oriundas de indústrias de laticínios, apresentando eficiência média de $96 \%$ na remoção de DQO e média de $93 \%$ na de turbidez.

A alcalinidade se manteve estável e em níveis adequados no reator, ao longo de praticamente todo o período de experimentação, indicando boa capacidade de tamponamento do sistema, exceto durante os períodos mais frios.

O tratamento de efluentes de laticínio com o uso do SGBR proporcionou atendimento à legislação para lançamento de efluentes em corpos hídricos, no que se refere aos parâmetros avaliados.

\section{AGRADECIMENTOS}

A FAPEMIG (APQ-01358-14) pelo financiamento da pesquisa.

\section{REFERÊNCIAS}

APHA_ AMERICAN PUBLIC HEALTH ASSOCIATION PRESS. Standard Methods for Examination of Water and Waste Water. 23nd. Washington: American Public Health Association Press, 2017.

BRASIL. Conselho Nacional de Meio Ambiente. Resolução CONAMA N. 430, de 13 maio de 2011. 2011.

BUCHAUER, K. A comparison of two simple titration procedures to determine volatile fatty acids in influents to waste-water and sludge treatment processes. Water SA, v. 24, p. 49-56, 1998.

CAMPOS, C. M. M.; LUIZ, F. A. R.; BOTELHO, C. G.; DAMASCENO, L. H. S. Avaliação da eficiência do reator UASB tratando efluente de laticínio sob diferentes cargas orgânicas. Ciência e Agrotecnologia, Lavras, v. 28, n. 6, p. 1376-1384, 2004. http://dx.doi.org/10.1590/S1413-70542004000600021

CHERNICHARO, C. A. L. Reatores anaeróbios: princípios do tratamento biológico de águas residuárias. Belo Horizonte: Segrac, 1997. 246.

DEBIK, E.; COSKUN, T. Use of the Static Granular Bed Reactor (SGBR) with anaerobic sludge to treat poultry slaughterhouse wastewater and kinetic modeling. Bioresource Technology, Essex, v. 100, n. 11, p. 2777 2782, 2009.2 DOI: https://dx.doi.org/10.1016/j.biortech.2008.12.058

ELLIS, T. G.; MACH, K. F. Static granular bed reactor. OFFICE, U. S. P. A. T. US. 6,709,591 2004.

EVANS, A. E.; ELLIS, G. T. Experimental Validation of the Static Granular Bed Reactor for Industrial Waste Anaerobic Treatment. Journal of Environmental Engineering, v. 136, n. 10, p. 1139-1146, 2010. DOI: http://dx.doi.org/10.1061/(ASCE)EE.1943-7870.0000256

FARIZOGLU, B.; UZUNER, S. The investigation of dairy industry wastewater treatment in a biological high performance membrane system. Biochemical Engineering Journal, Amsterdam, v. 57, p. 46-54, 2011. DOI: https://dx.doi.org/10.1016/j.bej.2011.08.007

JANCZUKOWICZ, W.; ZIELIŃSKI, M.; DĘBOWSKI, M. Biodegradability evaluation of dairy effluents originated in selected sections of dairy production. Bioresource Technology, Essex, v. 99, n. 10, p. 4199-4205, 2008. DOI: https://doi.org/10.1016/j.biortech.2007.08.077

LIM, S. J.; FOX, P. Evaluation of a static granular bed reactor using a chemical oxygen demand balance and mathematical modeling. Bioresource Technology, Essex, v. 102 , n. 11, p. 6399-6404, 2011. DOI: https://doi.org/10.1016/j.biortech.2011.03.031

OH, J. H.; PARK, J.; ELLIS, T. Performance of on-site pilot static granular bed reactor (SGBR) for treating dairy processing wastewater and chemical oxygen demand balance modeling under different operational conditions. Bioprocess and Biosystems Engineering, v. 38, n. 2, p. 353-363, 2014. DOI: https://dx.doi.org/10.1007/s00449014-1275-5

PARK, J.; OH, J. H.; EVANS, E. A.; LALLY, M. F.; HOBSON, K. L.; ELLIS, T. G. Industrial wastewater treatment by on-site pilot static granular bed reactor (SGBR). Water Practice and Technology, v. 7, n. 1, 2012. DOI: https://dx.doi.org/10.2166/wpt.2012.006

QUADROS, D. G. D.; OLIVER, A. D. P. M.; REGIS, U.; VALLADARES, R.; SOUZA, P. H. F.; FERREIRA, E. D. J. Biodigestão anaeróbia de dejetos de caprinos e ovinos em reator contínuo de PVC flexível. Revista Brasileira De Engenharia Agrícola E Ambiental, Campina Grande, v. $14, \quad$ n. 3 , p. 326-332, 2010. DOI: http://dx.doi.org/10.1590/S1415-43662010000300014

RODRIGUES, L. S.; SILVA, I. J.; ZOCRATO, M. C. O.; PAPA, D. N.; SPERLING, M. V.; OLIVEIRA, P. R. Avaliação de desempenho de reator UASB no tratamento de águas residuárias de suinocultura. Revista Brasileira de Engenharia Agrícola e Ambiental, Campina Grande, v. $14, \quad$ p. 94-100, 2010. DOI: http://dx.doi.org/10.1590/S1415-43662010000100013

SALÉH, B. B.; CLÁUDIO MILTON MONTENEGRO CAMPOS; FIGUEIREDO, J. G. D. Levantamento de parâmetros cinéticos medidos em reator anaeróbio de manta de lodo (UASB) em escala-piloto tratando efluentes de laticínio. Acta Scientiarum Technology, Maringá, v. 31 n. 1, p. 51-56, 2009. DOI: http://dx.doi.org/10.4025/actascitechnol.v31i1.823

SANTOS, K. D.; HENRIQUE, I. N.; SOUSA, J. T. D.; LEITE, V.D. Utilização de esgoto tratado na fertirrigação agrícola. Revista de Biologia e Ciências da Terra, n. 1, 2006.

SCHOENHALS, M.; FRARE, L. M.; SARMENTO, L. A. V. Análise do desempenho de reatores anaeróbios de fluxo ascendente e manta de lodo no tratamento de efluentes da suinocultura. Engenharia Ambiental, Espírito Santo do Pinhal, v. 4, n. 1, p. 5-23, 2007.

SZYMANSKI, M. S. E.; BALBINOT, R.; NAGEL, W. Biodigestão anaeróbia da vinhaça: aproveitamento energético do biogás e obtenção de créditos de carbono estudo de caso. Revista Semina: Ciências agrárias, Londrina, v. 31, n. 4, p. 901-912, 2010. DOI: http://dx.doi.org/10.5433/1679-0359.2010v31n4p901 